\title{
Decreasing the critical value of hemoglobin required for physician notification reduces the rate of blood transfusions
}

This article was published in the following Dove Press journal:

International Journal of General Medicine

3 June 2016

Number of times this article has been viewed

\author{
Eric A Larson' \\ Paul A Thompson ${ }^{1,2}$ \\ Zachary K Anderson ${ }^{3}$ \\ Keith A Anderson ${ }^{4}$ \\ Roxana A Lupu' \\ Vicki Tigner ${ }^{5}$ \\ Wendell W Hoffman ${ }^{6,7}$ \\ 'Department of Internal Medicine, \\ ${ }^{2}$ Department of Pediatrics, Sanford \\ School of Medicine, University \\ of South Dakota, Sioux Falls, SD, \\ ${ }^{3}$ Department of Internal Medicine, \\ Fairview Health Services, Edina, \\ MN, ${ }^{4}$ Department of Laboratory \\ Medicine, Sanford School of \\ Medicine, University of South \\ Dakota, ${ }^{5}$ Medical Staff Services, \\ ${ }^{6}$ Department of Infectious Disease, \\ Sanford Health, Sanford USD Medical \\ Center, ${ }^{7}$ Department of Infectious \\ Disease, Sanford School of Medicine, \\ University of South Dakota, Sioux \\ Falls, SD, USA
}

Correspondence: Eric A Larson Department of Internal Medicine, Sanford School of Medicine, University of South Dakota, I 205 S Grange Avenue 510, Sioux Falls, SD 57I05, USA

$\mathrm{Tel}+\mathrm{I} 6053518108$

Email Eric.Larson@Sanfordhealth.org

\begin{abstract}
Red blood cell transfusions have been cited as one of the most overused therapeutic interventions in the USA. Excessively aggressive transfusion practices may be driven by mandatory physician notification of critical hemoglobin values that do not generally require transfusion. We examined the effect of decreasing the critical value of hemoglobin from 8 to $7 \mathrm{~g} / \mathrm{dL}$ at our institution. Along with this change, mandatory provider notification for readings between 7 and $8 \mathrm{~g} / \mathrm{dL}$ was rescinded. Transfusion rates were compared retrospectively during paired 5-month periods for patients presenting in three key hemoglobin ranges (6.00-6.99, 7.00-7.99, and 8.00-8.99 g/dL). A change in transfusion practices was hypothesized in the $7-8 \mathrm{~g} / \mathrm{dL}$ range, which was no longer labeled critical and for which mandated physician calls were rescinded. Transfusion rates showed a statistically significant $8 \%$ decrease $(P \leq 0.0001)$ during the 5 -month period post change in our transfusion practices. This decrease in the $7.00-7.99 \mathrm{~g} / \mathrm{dL}$ range was significantly greater than the $2 \%$ decrease observed in either the $6-6.99 \mathrm{~g} / \mathrm{dL}(P=0.0017)$ or $8-8.99 \mathrm{~g} / \mathrm{dL}(P \leq 0.0001)$ range. Cost savings of up to $\$ 700,000 /$ year were extrapolated from our results showing 491 fewer units of red blood cells transfused during the 5-month post change. These cost savings do not take into account the additional impact of complications associated with blood transfusions.
\end{abstract}

Keywords: transfusion, critical value, hemoglobin, cost savings, red blood cells, transfusion complications

\section{Introduction}

Decades of research demonstrate that decreasing the overuse of red blood cell (RBC) transfusions improves patient outcomes and safety. ${ }^{1-3}$ Approximately one out of 400 RBC transfusions results in complications. ${ }^{4}$ The deleterious effects of transfusions are believed to be significantly underreported. ${ }^{4}$ The end results of various complications include increased length of hospital stay with increased morbidity and mortality. ${ }^{5}$

It has been suggested that increased notification of various abnormal laboratory values may result in improper referral to emergency departments and inappropriate interventions. ${ }^{6}$ Therefore, we felt that decreasing the critical value of hemoglobin for mandatory provider call from 8 to $7 \mathrm{~g} / \mathrm{dL}$ more accurately represents current standards and may improve physician adherence to evidence-based recommendations for transfusions.

Reducing transfusions in those less likely to benefit from the intervention is important to improve both patient care and cost-effectiveness of the health care system. The mean acquisition cost of procuring and processing packed RBCs in the USA in 2008 was \$223 per unit of whole blood. ${ }^{4}$ The cost of delivering a unit of packed RBCs in 2007 
was between $\$ 726$ and $\$ 1,183 .{ }^{7}$ This led to an estimated total cost per unit of packed RBCs delivered to be between $\$ 949$ and $\$ 1,416$. More recent financial estimates are not available but would be expected to be higher. These cost estimates do not include the expenses associated with complications of unnecessary RBC transfusions.

This study examines the effect of changing the critical value of hemoglobin and mandatory provider notification (from 8 to $7 \mathrm{~g} / \mathrm{dL}$ ) on the frequency of transfusion events and number of packed RBC units transfused.

\section{Methods}

In September 2013, the critical value of hemoglobin was decreased from 8 to $7 \mathrm{~g} / \mathrm{dL}$ at our community-based 545-bed hospital. Both laboratory and nursing staff completed training to modify their workflows highlighting that no physician notification from either nursing or laboratory staff would be made for hemoglobin between 7 and $8 \mathrm{~g} / \mathrm{dL}$ unless other clinical situations required notification. Physician notification was accomplished by a direct call from the laboratory staff to the nursing staff who relayed the result to the physician or appropriate call coverage. A hard stop in the electronic medical record (EMR) did not allow either the laboratory or nursing staff to proceed without completion of the notification. With this approach, $\sim 100 \%$ compliance is achieved. Physician compliance with return calls of clinical values is routinely monitored at our institution by routine critical laboratory monitoring. Physician callback compliance is achieved with a callback to the nursing staff during the 30-minute window after the nursing staff had paged the physician. Average compliance during the two most recent quarters was $91 \%$. During the period of modification of the provider guideline, no additional provider education efforts were instituted, but these had been ongoing over the past 3 years.

To assess the impact of this change, a retrospective analysis of comparable periods before and after policy change was conducted. Two 5-month periods (pre-change [Pre-C], September 2012-January 2013; post-change [Post-C], September 2013-January 2014) were selected to compare the proportion of transfusion requests resulting in transfusion as a function of hemoglobin level. Hemoglobin values were considered in three ranges (key ranges: 6.00-6.99, 7.00-7.99, and 8.00-8.99 g/dL). Over the two 5-month periods considered, all hemoglobin values in the three key ranges were analyzed for transfusion rate on a monthly basis. Values $<6.00 \mathrm{~g} / \mathrm{dL}$ were excluded as the clinical criteria for transfusion were met. Values $>9.00 \mathrm{~g} / \mathrm{dL}$ were excluded as these cases represented special or catastrophic circumstances.
Data were obtained from all adult inpatient medical and surgical units and intensive care units, including patients seen in the emergency department and subsequently admitted for further evaluation and treatment. We did not attempt to differentiate physician responsiveness to calls of critical values based on units in the hospital or by physician specialty. Patients aged 18 years or older were categorized based on the hemoglobin level. The primary outcomes were occurrence of transfusion and the number of packed RBC units administered.

Analysis was performed with generalized linear model methods using a binary link function. The three key ranges were compared using overall evaluation and designed specific comparisons of the ranges in Pre-C and Post- $\mathrm{C}$ pairs. If the primary changes (frequency of RBC transfusions and mean number of RBC units administered) were seen in the range of 7.00-7.99 g/dL, this would indicate that the change in the critical value and rescinded physician call was effective. Changes between Pre-C and Post-C pairs in the other two ranges (6.00-6.99 and 8.00-8.99 g/dL) were not expected, but were possible due to heightened awareness. The Institutional Review Board at Sanford Hospital viewed our study as a Quality Improvement project and IRB approval was waived and informed consent was not needed.

\section{Results}

Table 1 shows the percentages of all hemoglobin evaluations that resulted in a transfusion for key hemoglobin groups Pre-C and Post-C. The proportion transfused in the $7.00-7.99 \mathrm{~g} / \mathrm{dL}$ range decreased by $8 \%$ Post-C $(P \leq 0.0001)$. A $2 \%$ decrease in the proportion transfused Post-C was observed in both the 6.00-6.99 $\mathrm{g} / \mathrm{dL}(P=0.0078)$ and $8.00-8.99 \mathrm{~g} / \mathrm{dL}(P=0.0030)$ ranges. The $8 \%$ reduction in the $7.00-7.99 \mathrm{~g} / \mathrm{dL}$ range Post-C was significantly greater than either the $6.00-6.99 \mathrm{~g} / \mathrm{dL}(P=0.0017)$ or the $8.00-8.99 \mathrm{~g} /$ $\mathrm{dL}(P \leq 0.0001)$ range.

The cost savings of our policy changes were calculated by extrapolating the $6 \%$ decrease in the frequency of transfusions in the 7.00-7.99 $\mathrm{g} / \mathrm{dL}$ range to a 12-month period. An estimated total of 2,148 units of RBCs would have been transfused during the time period of our study (September 2013-January 2014) had the critical value not been changed. The difference in estimated and actual units transfused during this 5-month time period equals 204 units of RBC.

Extrapolating this estimate over a year suggests that there were 491 fewer units of RBCs transfused due to our policy changes. As discussed earlier, costs of procurement and delivery of RBCs vary widely, and recent data are not readily 
Table I Number of hemoglobin values in given ranges (n), proportion resulting in transfusion (P[Trx]), and mean number of units transfused (mean)

\begin{tabular}{|c|c|c|c|c|c|c|c|c|c|c|}
\hline \multirow[t]{3}{*}{ Period } & \multirow[t]{3}{*}{ Month, year } & \multicolumn{9}{|c|}{ Hemoglobin (g/dL) } \\
\hline & & \multicolumn{3}{|c|}{$6.00-6.99$} & \multicolumn{3}{|c|}{$7.00-7.99$} & \multicolumn{3}{|c|}{$8.00-8.99$} \\
\hline & & $\mathbf{n}$ & $P($ Trx $)$ & Mean & $\mathbf{n}$ & P(Trx) & Mean & $\mathbf{N}$ & $P($ Trx $)$ & Mean \\
\hline \multirow[t]{6}{*}{ Pre-C } & September 2012 & 43 & 0.88 & 6.6 & 173 & 0.91 & 6.0 & 483 & 0.66 & 5.5 \\
\hline & October 2012 & 49 & 0.94 & 5.1 & 264 & 0.82 & 4.6 & 709 & 0.67 & 4.8 \\
\hline & November 2012 & 35 & 0.83 & 3.4 & 257 & 0.84 & 4.1 & 721 & 0.70 & 4.1 \\
\hline & December 2012 & 56 & 0.77 & 4.7 & 213 & 0.81 & 3.7 & 739 & 0.62 & 4.7 \\
\hline & January 2013 & 63 & 0.78 & 7.6 & 342 & 0.84 & 6.0 & 993 & 0.61 & 5.7 \\
\hline & Total & 246 & 0.83 & 5.6 & $\mathrm{I}, 249$ & 0.84 & 4.9 & 3,645 & 0.65 & 4.9 \\
\hline \multirow[t]{6}{*}{ Post-C } & September 2013 & 37 & 0.89 & 7.1 & 293 & 0.75 & 6.0 & 622 & 0.66 & 5.7 \\
\hline & October 2013 & 93 & 0.75 & 9.2 & 423 & 0.81 & 8.4 & 842 & 0.60 & 6.6 \\
\hline & November 2013 & 98 & $0.7 \mathrm{I}$ & 4.1 & 417 & 0.74 & 5.1 & 775 & 0.63 & 4.0 \\
\hline & December 2013 & 69 & 0.94 & 4.2 & 346 & 0.82 & 3.2 & 755 & 0.65 & 3.4 \\
\hline & January 2014 & 67 & 0.84 & 4.0 & 371 & 0.70 & 3.5 & 882 & 0.61 & 3.1 \\
\hline & Total & 364 & 0.81 & 5.7 & 1,850 & 0.76 & 5.3 & 3,876 & 0.63 & 4.5 \\
\hline
\end{tabular}

Abbreviations: Pre-C, pre-change; Post-C, post-change.

available in the literature. This being stated, using data from 2007 and $2008,{ }^{1,3}$ we estimate the cost of procurement and delivery of one unit of RBCs at $\$ 1,416$. With the decrease in 491 units of RBCs transfused, we assume a cost savings of up to $\$ 700,000$ yearly.

\section{Conclusion and discussion}

There is consensus that decreasing $\mathrm{RBC}$ transfusions improve patient outcomes and safety. Literature demonstrating the direct harm to patients from overuse of RBC transfusions is compelling and has been well established over the past 2 decades. ${ }^{3}$ Even with this knowledge, a nurse call with a "critical value" of hemoglobin may influence physician utilization and impede adoption of current recommendations. Physicians may be particularly susceptible to a "critical" hemoglobin value because optimal parameters for intervention lack evidence $^{8}$ and are complicated by clinical settings. ${ }^{5}$ This understanding helped us to identify and remove potentially negative influences on physician adoption of current recommendations, minimizing transfusion overuse where potential harm exceeds potential benefit. ${ }^{1}$

We recognized that physician adoption of evolving recommendations is not easily altered by the generation of best practice guidelines alone. ${ }^{9,10}$ Our unique policy changes improved physician adherence to recommended clinical guidelines while improving patient safety and costeffectiveness. Specifically, our study showed that policy changes resulted in a statistically significant $6 \%$ decrease in blood transfusions (7.00-7.99 $\mathrm{g} / \mathrm{dL}$ range) and estimated 491 fewer units of RBCs transfused annually. A cost saving of up to $\$ 700,000 /$ year was extrapolated from our results, which do not include the known impacts of complications associated with blood transfusions.

In addition to decreased notification, we suspect that simply removing the label of critical to values of hemoglobin between 7 and $8 \mathrm{~g} / \mathrm{dL}$ decreased the likelihood of transfusions. With this type of policy change, it is essential to continually evaluate optimal critical values to ensure the proper balance between no notification and appropriate awareness. The presence of institutional oversight along with best practice advisories integrated into the electronic medical records is also critical to optimizing practice. ${ }^{11,12}$

This study outlines simple and easy to administer policy changes designed to influence physician response to reduce transfusions in those less likely to benefit from the intervention. We believe that our experience may be generalized to other situations in which there are unappreciated barriers to improving physician adherence to recommended clinical guidelines. Our study demonstrates that recognizing and removing potential negative influences on physician adoption of current recommendations may, at times, prove more fruitful than physician education, which occurs at great expense of time and resources.

\section{Disclosure}

The authors report no conflicts of interest in this work.

\section{References}

1. Crossing the Quality Chasm. Available from: http://goo.gl/uFVXtA. Accessed February 2, 2014.

2. Bulger J, Nickel W, Messler J, et al. Choosing wisely in adult hospital medicine: five opportunities for improved health-care value. J Hosp Med. 2013;8:486-492. 
3. The Joint Commission [webpage on the Internet]. Proceedings from the National Summit on Overuse, September 24, 2012. Available from: http://jointcommission.org/overuse.summit/. Accessed February 27, 2016.

4. Health and Human Services. The 2009 National Blood Collection and Utilization Survey Report. Washington, DC: US Department of Health and Human Services, Office of the Assistant Secretary for Health; 2011.

5. Marik PE, Corwin HL. Efficacy of red blood cell transfusion in the critically ill: a systematic review of the literature. Crit Care Med. 2008;36(9):2667-2674.

6. Kwon JH, Fausene MK, Hongyon D, Robicsek A, Peterson LR. Impact of laboratory-reported urine culture colony counts on the diagnosis and treatment of urinary tract infection for hospitalized patients. Am J Clin Pathol. 2012;137:778-794.
7. Stubbs JR. Wrapping our arms around the cost of transfusion therapy. Transfusion. 2014;54:259-262.

8. Gutsche JT, Kohl BA. When to transfuse: is it any surprise that we still don't know?* Crit Care Med. 2014;24(12):2647-2648.

9. Kosecoff J, Kanouse DE, Rogers WH, McCloskey L, Winslow CM, Brook RH. Effects of the NIH consensus development program on physician practice. JAMA. 1987;258:2703-2713.

10. Eisenstaedt RS. Modifying physicians transfusion practice. Transfus Med Rev. 1997;11:27-37.

11. Goodnough LT, Brecher ME, Kanter MH, AuBuchon JP. Transfusion medicine. First of two parts - blood transfusion. $N$ Engl J Med. 1999;340:438-447.

12. Ansari S, Szallasi A. Blood management by transfusion triggers: when less is more. Blood Transfus. 2012;10(1):28-33.

\section{Publish your work in this journal}

The International Journal of General Medicine is an international, peer-reviewed open-access journal that focuses on general and internal medicine, pathogenesis, epidemiology, diagnosis, monitoring and treatment protocols. The journal is characterized by the rapid reporting of reviews, original research and clinical studies across all disease areas.
A key focus is the elucidation of disease processes and management protocols resulting in improved outcomes for the patient. The manuscript management system is completely online and includes a very quick and fair peer-review system. Visit http://www.dovepress.com/ testimonials.php to read real quotes from published authors. 